\title{
Resuspension and estuarine nutrient cycling: insights from the Neuse River Estuary
}

\author{
D. R. Corbett \\ Department of Geological Sciences, Institute for Coastal Science and Policy, East Carolina University, Greenville, \\ North Carolina, USA
}

Received: 29 March 2010 - Published in Biogeosciences Discuss.: 16 April 2010

Revised: 6 October 2010 - Accepted: 19 October 2010 - Published: 26 October 2010

\begin{abstract}
For at least the past several decades, North Carolina's Neuse River Estuary (NRE) has been subject to water quality problems relating to increased eutrophication. Research initiated in the past several years have addressed the nutrient processes of the water column and the passive diffusion processes of the benthic sedimentary environment. Resuspension of bottom sediments, by bioturbation, tides, or winds, may also have a significant effect on the flux of nutrients in an estuarine system These processes can result in the advective transport of sediment porewater, rich with nitrogen, phosphorus and carbon, into the water column. Thus, estimates of nutrient and carbon inputs from the sediments may be too low.
\end{abstract}

This study focused on the potential change in bottom water nutrient concentrations associated with measured resuspension events. Previous research used short-lived radionuclides and meteorological data to characterize the sediment dynamics of the benthic system of the estuary. These techniques in conjunction with the presented porewater inventories allowed evaluation of the depth to which sediments have been disturbed and the advective flux of nutrients to the water column. The largest removal episode occurred in the lower NRE as the result of a wind event and was estimated that the top $2.2 \mathrm{~cm}$ of sediment and corresponding porewater were removed. $\mathrm{NH}_{4}^{+}$advective flux (resuspended) was 2 to 6 times greater than simply diffusion. Phosphate fluxes were estimated to be 15 times greater than the benthic diffusive flux. Bottom water conditions with elevated $\mathrm{NH}_{4}^{+}$and $\mathrm{PO}_{4}^{3-}$ indicate that nutrients stored in the sediments continue to play an important role in overall water quality and this study suggests that the advective flux of nutrients to the water column is critical to understand estuarine nutrient cycling.

Correspondence to: D. R. Corbett (corbettd@ecu.edu)

\section{Introduction}

In most estuaries, the amount of nutrients supplied by external sources (e.g. atmospheric deposition, river runoff, nitrogen fixation) has consistently been shown to supply less than that required by primary producers (Dugdale and Goering, 1967; Haines, 1976; Windom et al., 1975; Nixon, 1981; Stanley and Hobbie, 1981; Fisher et al., 1982; Boyer et al., 1988). The remainder of the nutrient supplies must, therefore, come from in situ regeneration and recycling. A major component of this internal recycling is exchange at the benthic boundary. The benthic environment is particularly important due to the large portion of organic matter that reaches the sediment surface after settling out of the water column. This organic matter is then remineralized, a process during the decomposition of organic matter where inorganic nutrients, such as nitrogen and phosphorus, are released, thus increasing their concentrations in the interstitial waters. The newly regenerated nutrients are then transported back to the water column through exchange with overlying waters. In most shallow-water systems, surficial sediments and the overlying water are continually interacting, exchanging and redistributing particles and solutes, making this recycling process extremely important for understanding nutrient dynamics in the estuarine environment (Wells and Kim, 1989; Rizzo, 1993; Rizzo and Christian, 1996; Luettich et al., 2000). However, the exchange of solutes from the sediments to the overlying water is often quantified assuming the benthic environment is passive, ignoring extremely dynamic events such as resuspension that would move nutrients rapidly to the water column. This study provides an estimate of the additional flux of nutrients that are released to the water column associated with sediment resuspension events in the Neuse River Estuary (NRE), North Carolina. Through the use of short-lived radioisotopes, meteorological data and in situ physical measurements (e.g., turbidity, currents) to determine the spatial and temporal variability and magnitude

Published by Copernicus Publications on behalf of the European Geosciences Union. 


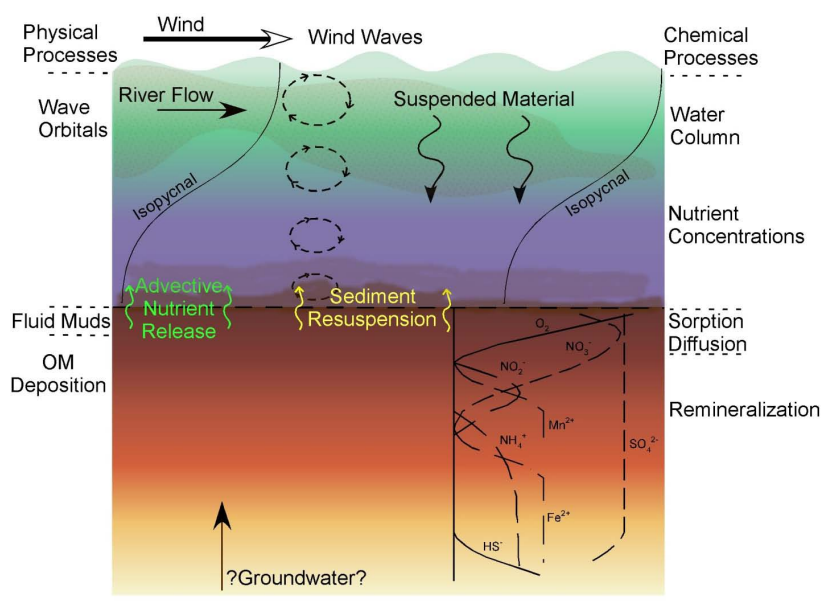

Fig. 1. Sediment processes in an estuary influence the nutrient load to surface waters. Nutrients may be introduced to the water column through both passive (diffusion, desorption, etc.) and advective (groundwater advection, resuspension, biological mixing, etc.) processes (modified from Giffin and Corbett, 2003).

of resuspension events the following specific objectives were addressed: (1) evaluate the benthic contribution of nutrients to the water column by characterizing changes in porewater concentrations during both passive and disturbed periods at selected sites; and (2) determine the overall effectiveness of sediment resuspension and remobilization in introducing diagenetic end-products from porewaters into overlying coastal waters.

\section{Background}

\subsection{Sediment resuspension and nutrient delivery}

The seasonal storage and remobilization of sediments in rivers is a worldwide phenomenon that has been described for rivers ranging in size from small streams (Emmett et al., 1983; Meade et al., 1990) to the Amazon (Meade et al., 1985). During the sediment storage phase, rates of sediment deposition to the seabed may be relatively high and the resulting sediment deposits remain undisturbed for periods of weeks to months. These conditions and time scales are conducive to a number of significant chemical transformations (i.e. remineralization, oxic/anoxic cycles, etc.) within the bottom sediments. Determining what role sediments play on basin-scale nutrient dynamics and elucidating the factors that control net nutrient exchanges have important implications for understanding nutrient flux and production dynamics in both estuarine and coastal oceanic environments.

Estuarine sediments and associated porewaters are exposed to complex biogeochemical and physical processes (Fig. 1) that influence sediment/porewater composition as well as material (e.g. nutrients) fluxes to the water column.
Estuarine sediments normally have an oxic zone of $5 \mathrm{~mm}$ or less and is often absent below $1 \mathrm{~mm}$ (Fenchel, 1992). Below this zone, several reductive processes occur which degrade organic material in a known sequence. In addition, river currents, winds, and tides are some of the physical processes that have impacts on sediment deposition, and ultimately nutrient distribution. In shallow estuaries, winds create waves that in turn develop orbital velocities with enough force to resuspend sediments and release their porewaters to the overlying water column. Winds can also break down stratification and force nutrient-rich bottom water to the surface, promoting algal blooms. Resuspended sediment in these shallow estuaries has other impacts, through light limitation and consequent reductions in primary production.

Studies that compared the nutrient flux associated with stable (passive) sediments and recently resuspended sediments found significantly higher fluxes associated with the latter (Fanning et al., 1982; Kristensen et al., 1992; Sondergaard et al., 1992; de Jonge et al., 1995). The basic processes and driving forces of resuspension and sediment transport have been described in detail (e.g., Hakanson and Jansson, 1983; Carper and Bachman, 1984; Hilton et al., 1986; Bengtsson et al., 1990; Luettich et al., 1990; Weyhenmeyer et al., 1997; Douglas and Rippey, 2000). Lam and Jaquet (1976) suggested that threshold current velocities of $2-3 \mathrm{~cm} \mathrm{~s}^{-1}$ were sufficient to resuspend non-cohesive clay and silt particles, although other studies have found that current velocities must exceed $10 \mathrm{~cm} \mathrm{~s}^{-1}$ to move unconsolidated fine particles (Postma, 1967; Douglas and Ripley, 2000). Studies conducted in the lower NRE have shown near bottom currents as high as $20 \mathrm{~cm} \mathrm{~s}^{-1}$, with an average current at or below $5 \mathrm{~cm} \mathrm{~s}^{-1}$ (Woods, 1969; Luettich et al., 2000; Giffin and Corbett, 2003; Dillard, 2008). Thus, resuspension may be prevalent throughout the year in the NRE. However, wind-induced waves, producing orbital movement in the water column, are the dominant process causing resuspension of sediments in this system (Dillard, 2008).

\subsection{Water quality in the NRE}

Massive summer fish kills in 1995 drew public attention to deteriorating water quality in the Neuse River and its estuary (Luettich et al., 2000). For at least the past several decades, North Carolina's NRE (Fig. 2) has been subject to water quality problems relating to increased eutrophication, a condition caused by loading of excessive nutrients, primarily nitrogen. Eutrophication has been shown to lead to stress and loss of fisheries, losses in biodiversity, and alteration of food webs (Nixon, 1981). Sources of nutrient enrichment to the estuary are from fertilizers, precipitation, livestock, and point sources (Spruill et al., 1998). Fertilizer and precipitation are listed as the primary nitrogen sources with precipitation contributing as much as 15 to $32 \%$ of new nitrogen (Paerl et al., 2002). This nutrient loading has resulted in toxic algal blooms and bottom water hypoxia/anoxia in this 


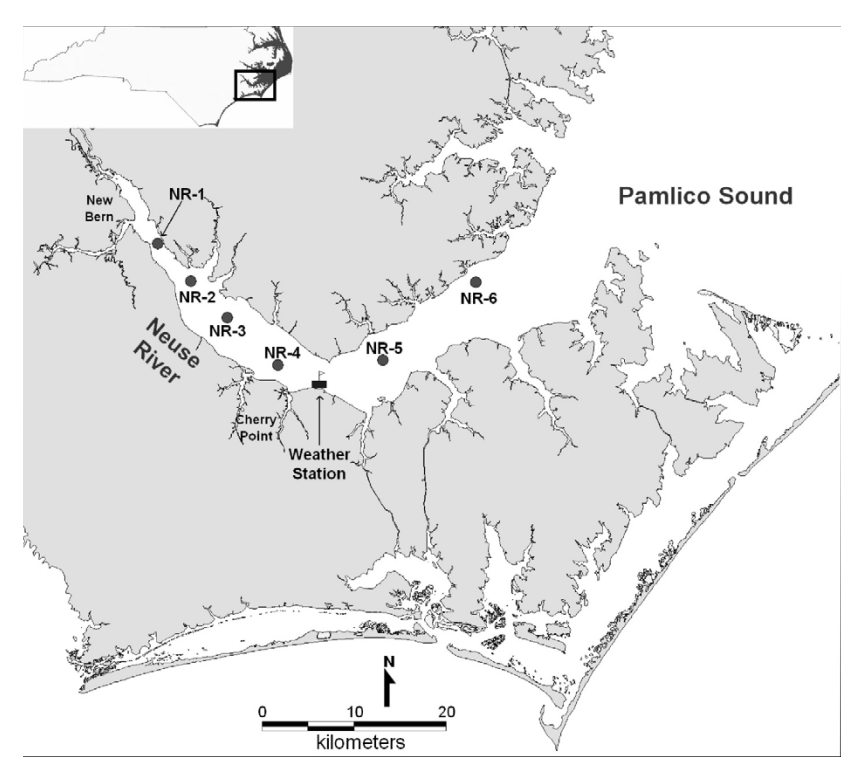

Fig. 2. Sampling locations in the Neuse River Estuary were selected over various salinities, ranging from oligohaline to mesohaline environments. Stations are numbered with the lowest number (NR-1) upriver, increasing sequentially down-estuary.

shallow and dynamic system (Luettich et al., 2000) mostly as the result of increased agriculture, industrialization, and urban development. In addition, seasonal pulsing of nutrients, salinity and temperature stratification and proximity to these nutrient sources all act to further aggravate this condition. Much of the nutrient-related research in the NRE has focused on water column processes and passive diffusion of the sedimentary environment, stating that diffusion is one of the dominant transport processes delivering nutrients to the water column (Fisher et al., 1982; Luettich et al., 2000). These studies have employed benthic flux chambers, typically Plexiglas cylindrical chambers placed over a known area of sediment and equipped with inlet and outlet ports to collect water samples at varying time intervals. Fick's law has also been applied to concentration gradients across the sediment/water interface to quantify the nutrient flux from the sediment bed. Fick's law is used to simulate the rate of diffusive mass transport (Kirkham and Powers, 1972). In these examples, experiments were specifically designed to prevent any porewater exchange due to the disturbance of the sediment bed, e.g. sediment resuspension. Therefore, these estimates are based on a quiescent benthic environment and have not yet accounted for the nutrient contribution associated with any disturbance of the sediments due to winds or waves. It is important to note that Wells and Kim (1989) believe that most of the surface sediments within the Neuse River trunk estuary will be deposited and resuspended many times before permanent accumulation on the bottom. This is due to the fine-grained nature (silts and muds) of the sediments, the shallow water character of the sediment basin,

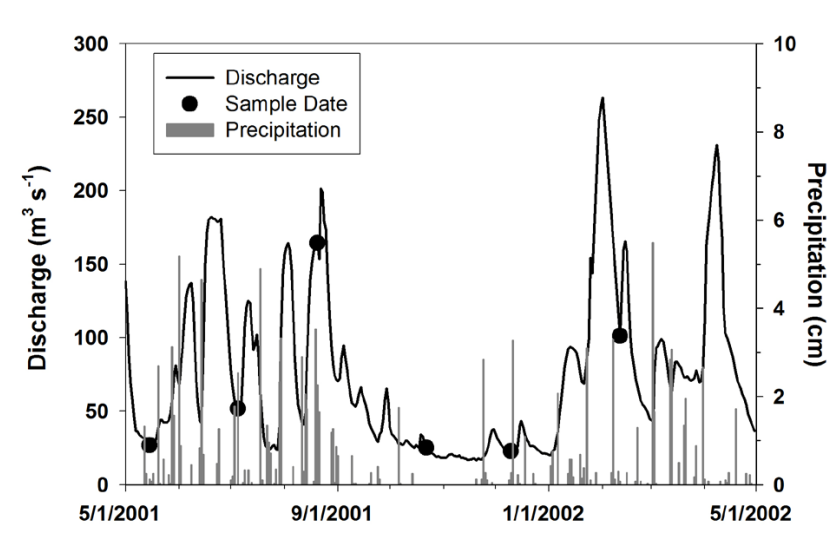

Fig. 3. Discharge and precipitation for the study year. Precipitation data is from New Bern, NC and discharge data is from the gaging station at Fort Barnwell (approximately $33 \mathrm{~km}$ upstream from New Bern) on the Neuse River. Note that sediment removals occurred during periods of increased precipitation and river discharge.

and the high levels of wind stress on the basin (Riggs et al., 1991). Thus, it is necessary to understand the dynamics of these resuspension events, including the aerial extent over which they occur and the frequency, and the potential impact they may have on surface.

\section{Study area}

The NRE (Fig. 2) is a drowned river valley draining large basins originating in the Piedmont which eventually flows through the coastal plain and then empties into Pamlico Sound. The watershed covers approximately $16000 \mathrm{~km}^{2}$ and the average depth is about $4.6 \mathrm{~m}$ (Matson et al., 1983) supplying a large portion of freshwater flow to Pamlico Sound. At the mouth of the Neuse, the average annual discharge has been calculated at $150 \mathrm{~m}^{3} \mathrm{~s}^{-1}$ (Wells and Kim, 1989). During this study, measurements of daily discharge at Fort Barnwell, a US Geological Survey river gauging station just upstream of where the river meets the estuary (e.g., New Bern), ranged from a low of approximately $14.2 \mathrm{~m}^{3} \mathrm{~s}^{-1}$ to a high of $255 \mathrm{~m}^{3} \mathrm{~s}^{-1}$. Peak flows typically occur during the spring; however during this study, they occurred primarily in late summer 2001 and in late winter of 2002 (Fig. 3). Low flow occurred during late fall and early winter instead of typically during late summer and early fall.

The distribution of surficial sediments within this estuary is influenced by the bathymetry of the basin and flow processes. Fine to medium grained sands are found at the shorelines, while finer grained sands and silts and organic rich muds (ORM) are found in the deeper portions (Pilkey et al., 1998). ORM has been typified as being chemically active organic-rich sediment acting as both a nutrient sink and source (Riggs, 1996). As a sink, these sediments provide a depositional site for carbon and nitrogen. These sediments 


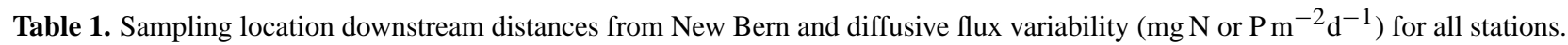

\begin{tabular}{lllllllll}
\hline & $\begin{array}{l}\text { Distance Downstream } \\
\text { Station Number }\end{array}$ & High & $\begin{array}{l}\mathrm{NH}_{4}^{+} \\
\text {Low }\end{array}$ & Mean & High & $\begin{array}{l}\mathrm{PO}_{4}^{3-} \\
\text { Low }\end{array}$ & \multicolumn{2}{c}{ Mean } \\
\hline NR-1 & 5 & 12.4 & 3.8 & 8.8 & 5.6 & 1.8 & 2.6 & $8.0 \pm 4.6$ \\
NR-2 & 13.3 & 25.2 & 1.3 & 13.3 & 9.7 & 0.1 & 3.5 & $9.5 \pm 3.8$ \\
NR-3 & 21.7 & 64.6 & 2.1 & 17.8 & 8.2 & 0.4 & 3.0 & $11.9 \pm 2.9$ \\
NR-4 & 32.5 & 13.2 & 1.5 & 8.9 & 3.9 & 0.1 & 1.9 & $12.8 \pm 2.7$ \\
NR-5 & 49.2 & 31 & 6.1 & 16.6 & 6.8 & 0.7 & 3.2 & $15.3 \pm 3.1$ \\
NR-6 & 69.2 & 22 & 10.4 & 15.6 & 7.3 & 0.3 & 4.0 & $16.6 \pm 3.0$ \\
\hline
\end{tabular}

then enable enhanced remineralization, which provides a reservoir of these nutrients to porewaters where they become a source available for both passive and advective flux to the overlying water column.

Sample locations were chosen near the center of the river in the finer grained ORM areas. Six sites (Fig. 2) were located in the NRE covering a salinity range of $0-10$ in the vicinity of the Trent River tributary up to the mesohaline waters near the juncture with Pamlico Sound. Distances downstream from New Bern are shown in Table 1.

\section{Methods}

Samples were collected approximately every 6-7 weeks at six locations in the NRE (Fig. 2) in 2001 and 2002 (Fig. 3). Cores were collected by push core from a small boat with a PVC coring device outfitted with a one-way check valve and a $\sim 10 \mathrm{~cm}$ diameter clear acrylic tube (core tube). The sample core tube was gently pushed into the bottom sediments to obtain a vertical column of sediment without disturbing the interface. Cores were subsectioned along the length of the core $(\sim 19 \mathrm{~cm})$. The upper two subsections extruded in the field were $2 \mathrm{~cm}$ thick and the remaining subsections were $3 \mathrm{~cm}$ each. A $20 \mathrm{ml}$ sample of each subsection was taken for porosity calculations. The remaining sediment from each extruded interval was immediately transferred to centrifuge tubes and sealed (with no air space) with a tight fitting plastic end cap and stored on ice. Upon return to the laboratory, samples were centrifuged and syringe filtered to separate the dissolved phase from the solid phase. Dissolved samples were analyzed for total and organic/inorganic nitrogen and phosphate.

Water column samples were collected from just above the bottom and near the surface at each site using a peristaltic pump. Conductivity, temperature, salinity, and dissolved oxygen (DO) were measured at these same intervals using YSI meters. Water samples were filtered through preweighed combusted Whatman GFF filters $(0.7 \mu \mathrm{m} ; 47 \mathrm{~mm}$ diameter) and filters were saved for total suspended solid analysis. Dissolved fractions were collected (after in-line fil- tration) in acid-cleaned polyethylene bottles. Samples were kept on ice until analysis.

Surface water and porewater samples were analyzed for ammonium $\left(\mathrm{NH}_{4}^{+}\right)$using the Solorzano method (Solorzano, 1969) and for dissolved nitrate plus nitrite $\left(\mathrm{NO}_{3}^{-}+\mathrm{NO}_{2}^{-}\right)$and phosphate $\left(\mathrm{PO}_{4}^{3-}\right)$ using US EPA (1979) and American Public Health Association (1995) methods. Previous studies have shown that nitrite is barely detectable in comparison to nitrate (Luettich et al., 2000) therefore $\mathrm{NO}_{3}^{-}+\mathrm{NO}_{2}^{-}$results are presented as nitrate $\left(\mathrm{NO}_{3}^{-}\right)$. Filters were dried at $105^{\circ} \mathrm{C}$ for at least $24 \mathrm{~h}$.

\section{Results}

\subsection{Water column nutrients}

The physical parameters, salinity, DO, and TSS were strongly influenced by low flow conditions that limited discharge through the end of 2001 (Fig. 3). A distinct saltwater wedge could be seen in the upper region of the estuary throughout most of the year with high salinities in the bottom water up to $\sim 15$, and relatively lower salinities in the surface water ranging from several to more than 10 . The lower estuary showed little difference in surface and bottom salinities, typically ranging from 10 to 20 , indicating well mixed conditions. Temporally, the wedge showed a steady increase in salinity up-estuary until fall and early winter where it exhibited a slight decrease. DO levels in surface water maintained well above hypoxic conditions $\left(<2 \mathrm{mg} \mathrm{l}^{-1}\right)$ with levels above $5 \mathrm{mg} \mathrm{l}^{-1}$ throughout the entire sampling period. Hypoxic conditions were observed with nearly anoxic levels in bottom waters of the upper estuary (Stations 1-3) and in portions of the lower estuary (Stations 4 and 5). For much of the year the lowest levels were observed at Station 2 with concentrations $<1 \mathrm{mgl}^{-1}$ for 5 of the 6 sample periods. This area is close to the locations of documented fish kills that occurred during the sampling timeframe. TSS ranged from a median of 5.5 to $7.2 \mathrm{mg} \mathrm{l}^{-1}$ for 5 of the 6 sample periods. During the high flow period in February 2002 (Fig. 3) the median reached $33.3 \mathrm{mg} \mathrm{l}^{-1}$, thus showing that TSS is strongly influenced by river discharge. Temperature measurements 


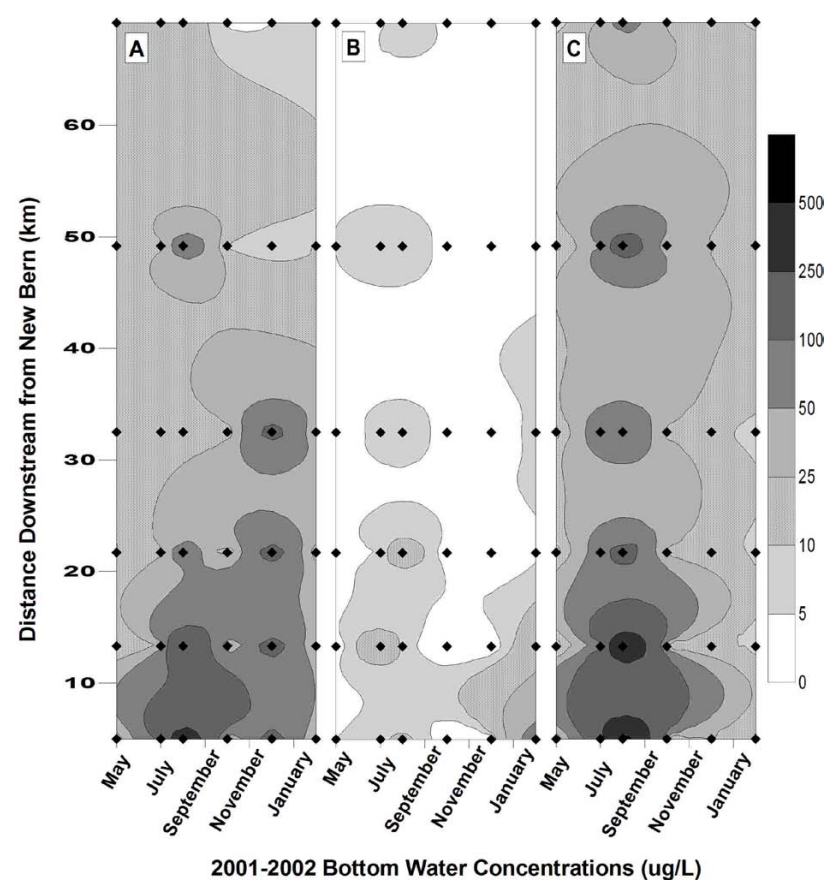

Fig. 4. Concentrations (ug $\mathrm{N}$ or $\mathrm{P}^{-1}$ ) of (A) $\mathrm{NH}_{4}^{+}$, (B) $\mathrm{NO}_{3}^{-}$, and (C) $\mathrm{PO}_{4}^{3-}$ in bottom waters of the Neuse River estuary for May 2001 through early spring 2002. Contours are interpolated between sampling events (i.e., time) and sites.

showed a consistent temporal distribution in both surface and bottom waters, ranging from a high of $28^{\circ} \mathrm{C}$ in the summer to a low of $9^{\circ} \mathrm{C}$ in the winter. There was only slight variation of a few degrees Celsius in the water column between surface and bottom waters occurring primarily in the summer months when bottom waters were slightly cooler. Spatial distributions were fairly uniform throughout the estuary.

Ammonium $\left(\mathrm{NH}_{4}^{+}\right)$concentrations in the surface water, ranging from 2 to $166 \mu \mathrm{g} \mathrm{N}^{-1}$, were typically greater upestuary decreasing toward the estuary mouth. The highest levels were in August and December and lowest in October. Ammonium exhibited the same distribution in bottom waters (Fig. 4), ranging from 3 to $418 \mu \mathrm{g} \mathrm{N}^{-1}$, as it did in surface waters; however concentrations were more elevated in the summer months. Nitrate concentrations in surface water were highest in August and lowest in October, ranging from 1 to $467 \mu \mathrm{g} \mathrm{N}^{-1}$, with a generally decreasing trend downriver towards the estuary mouth. Bottom water $\mathrm{NO}_{3}^{-}$concentrations (Fig. 4) ranging from 0.1 to $72 \mu \mathrm{g} \mathrm{N} 1^{-1}$, were highest in February and showed the same spatial pattern as surface water concentrations. Surface water phosphate concentrations were highest in the summer months and lowest in winter and spring, ranging from 0.1 to $246 \mu \mathrm{P} \mathrm{P}^{-1}$, with a spatial distribution that exhibited a mid-estuary maximum. The same temporal trend (Fig. 4), ranging from 2 to $616 \mu \mathrm{g} \mathrm{Pl}^{-1}$, was observed in the bottom waters. However, concentrations were highest in the upper reach of the estuary and gradually declined towards the mouth of the estuary.

\subsection{Porewater nutrients and diffusive flux}

Vertical profiles of porewater $\mathrm{NH}_{4}^{+}$concentrations for the top $10 \mathrm{~cm}$ of sediment cores exhibited increasing concentrations with depth for all stations with only a few exceptions. The $\mathrm{NH}_{4}^{+}$concentrations ranging from 0.5 at the mid-estuary locations to $15.7 \mathrm{mg} \mathrm{N}^{-1}$ at NR-6 in the Neuse (Fig. 5) generally displayed a temporal distribution with highest levels in late summer and lowest in spring. The lowest $\mathrm{NH}_{4}^{+}$level was in the surficial sediment at NR-4 in May while the highest was at depth $(7-10 \mathrm{~cm})$ at NR-6 in August. Levels generally increased downstream to Station 2, an area of documented fish kills, and then decreased towards Cherry Point where they once again gradually increased to their highest levels near the river mouth. The distribution of $\mathrm{PO}_{4}^{3-}$ concentrations, ranging from 0.2 to $13.1 \mathrm{mg} \mathrm{Pl}^{-1}$ (Fig. 6), displayed the same general trends as porewater $\mathrm{NH}_{4}^{+}$concentrations.

Porewater nitrate and nitrite (not illustrated) ranging from 0.002 to $0.06 \mathrm{mg} \mathrm{N}^{-1}$ exhibited the same spatio-temporal distribution as surface water $\mathrm{NO}_{3}^{-}$and $\mathrm{NO}_{2}^{-}$. It can readily be seen that nitrate-nitrite concentrations, as intermediates in sediment $\mathrm{N}$ redox reactions, compose a very small amount of the total porewater nitrogen in comparison to ammonium, generally representing $<1 \%$ of the total $N$. Although cores were not sectioned under an $N$-environment and therefore some $N$-species change associated with redox variations cannot be ruled out, the dominance of ammonium in porewaters do not support significant oxygenation of the sediment during sampling.

The flux across a sediment interface has traditionally been assumed to be controlled by molecular diffusion and can be calculated using the following widely used variation of Fick's first law of diffusion (Berner, 1980):

$J=\phi_{0} D_{s}(\partial C / \partial Z)_{z=0}$

where $\phi_{0}$ is the porosity, $D_{S}$ is the effective wet bulk sediment diffusion coefficient in the sediments $\left(\mathrm{m}^{2} \mathrm{~min}^{-1}\right)$ corrected for temperature and tortuosity and $(\delta C / \delta Z)_{z=0}$ is the porewater nutrient concentration gradient in the uppermost sediments. Porosity values were typically $\sim 0.9$ in the uppermost sediments. Using this relationship, diffusive flux (Table 1) was determined at all stations for the high, low and mean passive flux. Diffusive $\mathrm{NH}_{4}^{+}$flux was predominantly highest during the summer months and lowest in spring with an overall mean of $13.5 \mathrm{mg} \mathrm{m}^{-2} \mathrm{~d}^{-1}$. Diffusive $\mathrm{PO}_{4}^{3-}$ flux followed the same temporal distribution as the $\mathrm{NH}_{4}^{+}$, however the overall mean was an order of magnitude less at $3.0 \mathrm{mg} \mathrm{m}^{-2} \mathrm{~d}^{-1}$. Highest diffusive fluxes for $\mathrm{NH}_{4}^{+}$and $\mathrm{PO}_{4}^{3-}$ were typically found in the mid-estuary, e.g. NR-3. 
Porewater Ammonium Concentration (mg N I-1)
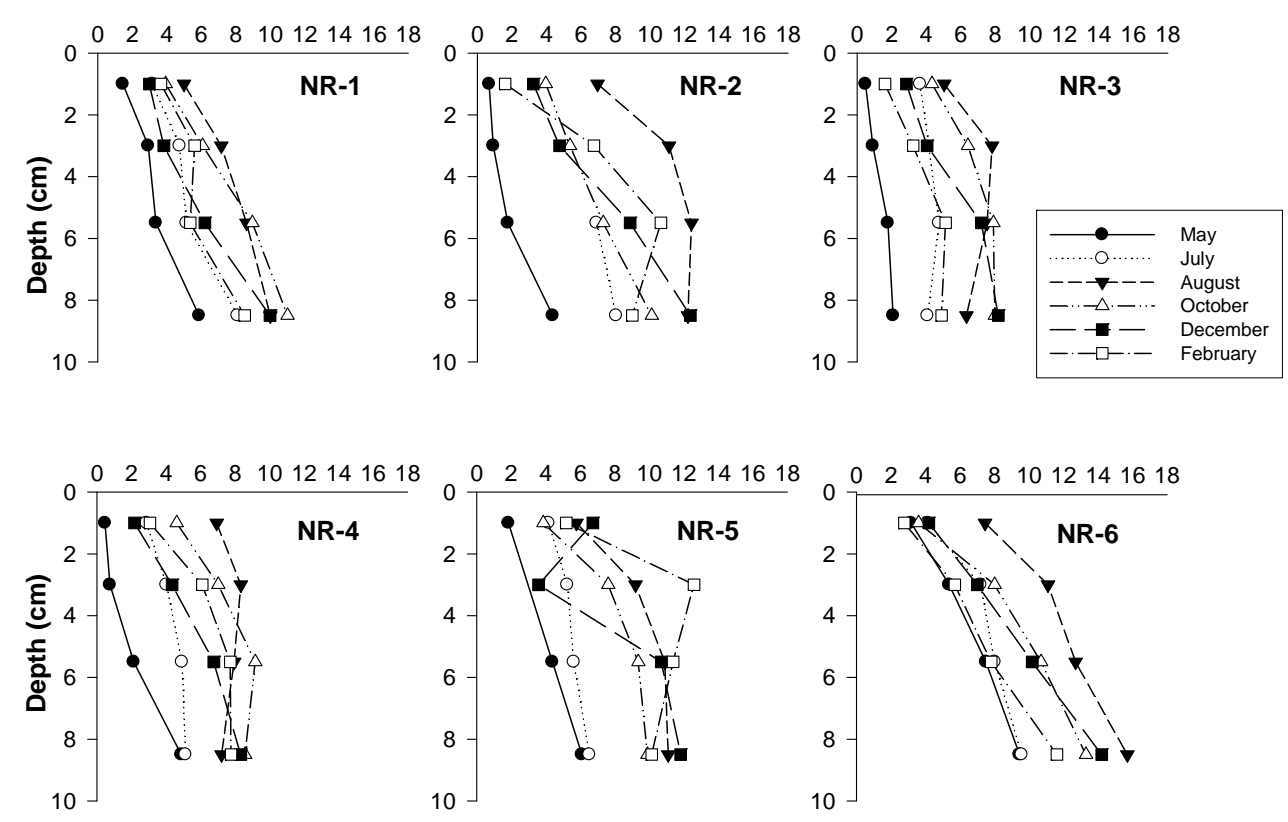

Fig. 5. Porewater concentrations for $\mathrm{NH}_{4}^{+}$in the NRE for May 2001 through February 2002.

\section{Porewater Phosphate Concentration (mg P $\left.\mathbf{~ I}^{-\mathbf{1}}\right)$}
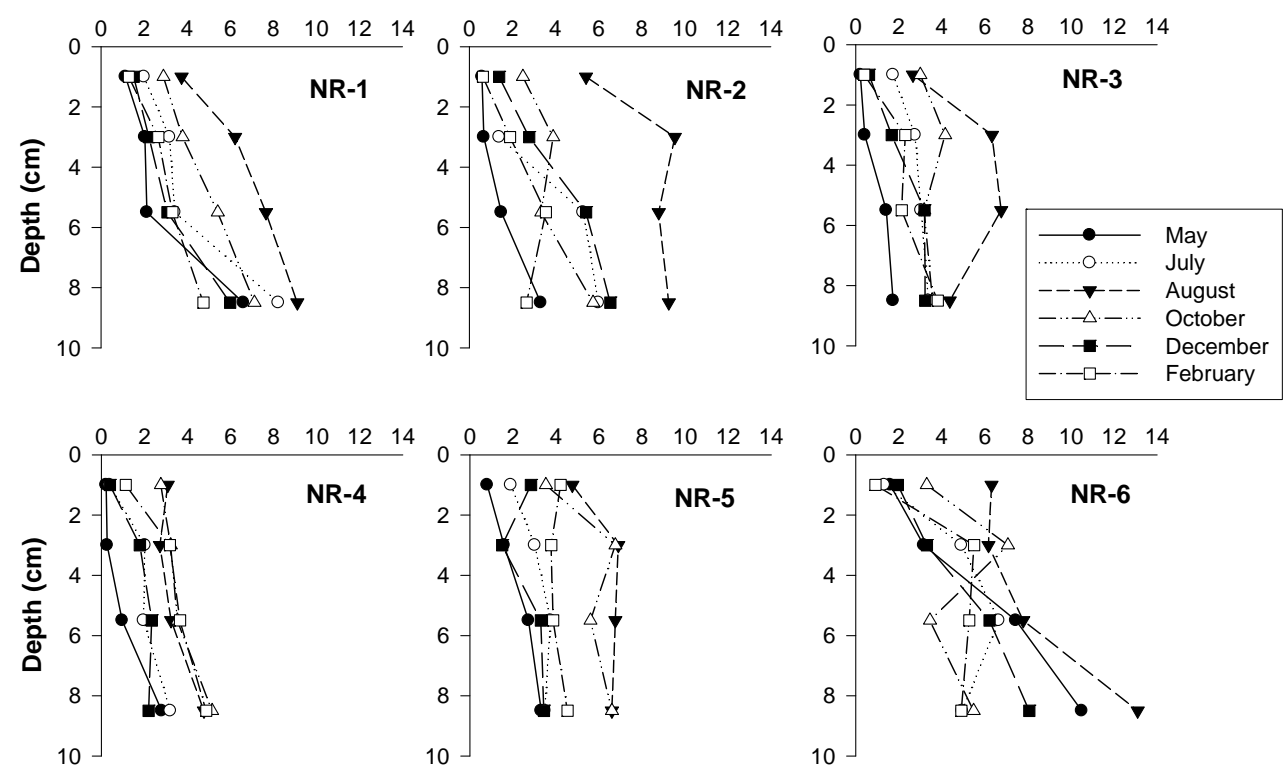

Fig. 6. Porewater concentrations for $\mathrm{PO}_{4}^{3-}$ in the NRE for May 2001 through February 2002.

\subsection{Sediment resuspension in the NRE}

Resuspension events in the NRE were investigated by using short-lived radioisotopes to understand short-term sediment dynamics (see Giffin and Corbett, 2003). Samples from all sediment cores were analyzed for ${ }^{234} \mathrm{Th}\left(\mathrm{t}_{1 / 2}=24.1\right.$ days) and ${ }^{7} \mathrm{Be}\left(\mathrm{t}_{1 / 2}=53.3\right.$ days $)$ by direct gamma counting. Gamma counting was conducted on one of two lowbackground, high-efficiency, high-purity Germanium detectors (Coaxial- and Well-type) coupled with a multi-channel analyzer. Sediment ${ }^{7} \mathrm{Be}$ and ${ }^{234} \mathrm{Th}$ inventories were calculated from downcore activities (Canuel et al., 1990). 
Variations in the inventories of short-lived nuclides between sampling periods provide evidence of no deposition, removal, or new deposition (see Giffin and Corbett, 2003). Although changes in salinity and precipitation may alter the inventory of ${ }^{234} \mathrm{Th}$ and ${ }^{7} \mathrm{Be}$, respectively, Giffin and Corbett (2003) argued that changes in the radiochemical inventory were most likely driven by variations in sedimentation. Comparisons of total ${ }^{234} \mathrm{Th}$ inventory to bottom water salinity in the estuary, especially the upper portion where seasonal variation is greatest, did not demonstrate large variations associated with salinity changes (Giffin and Corbett, 2003). Therefore, ${ }^{234} \mathrm{Th}$ inventory fluctuations are thought to be associated with sediment delivery and transport. The daily precipitation data show a fairly uniform distribution throughout the year of the study with the notable exception of the low precipitation of the October to November timeframe. Comparison of this data to the ${ }^{7} \mathrm{Be}$ total inventory showed no observable decline during the late fall when precipitation was at its lowest (Giffin and Corbett, 2003). A major source of ${ }^{7} \mathrm{Be}$ to the estuary is sediments delivered through basin-wide runoff. The area of the basin is relatively large compared to that of the estuary, reducing the effects of short-term rainfall variations. Giffin and Corbett (2003) found ${ }^{7} \mathrm{Be}$ to be a better tracer of resuspension events in this system and attributed it to the time scale of sampling relative to the mean life of the nuclides and a greater source of ${ }^{7} \mathrm{Be}$ associated with the watershed size.

The amount of sediment resuspended in a removal episode can be calculated using the difference in the total radionuclide inventory lost between two sampling events (accounting for decay between sampling) in $\mathrm{dpm} \mathrm{cm}^{-2}$ and estimating the surface activity that is resuspended $\left(\mathrm{dpm} \mathrm{g}^{-1}\right.$, an average of the top $5 \mathrm{~cm}$ was used). This calculation gives the amount of sediment resuspended $\left(\mathrm{g} \mathrm{cm}^{-2}\right)$ assuming the sediment can be transported. Using a simple relationship developed by Hjulstrom (Pipkin, 1994), where the grain size and current velocity are known, the critical erosion velocity can be evaluated. Grain size analysis showed primarily silts and fine sands at surface with downcore median diameters of 23$155 \mathrm{um}$ in the NRE with no fining sequences vertically or laterally throughout the estuaries (Giffin and Corbett, 2003). Variations in ${ }^{7} \mathrm{Be}$ and ${ }^{234} \mathrm{Th}$ inventories provided good indications of deposition and removal processes in this estuarine environment indicating that the main deposition area for the NRE occurs primarily around NR-3 and NR-4. The largest sediment removal was observed during August 2001 at stations NR-4 through NR-6 and another significant removal was seen during February 2002 at stations NR-2, NR-5, and NR-6. These areas are most susceptible to wind driven sediment disturbances. The removal in August 2001 at NR-6 had

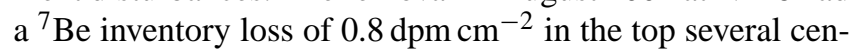
timeters where the ${ }^{7} \mathrm{Be}$ activity measured was $1.8 \mathrm{dpm} \mathrm{g}^{-1}$ or an approximate loss of $0.4 \mathrm{~g} \mathrm{~cm}^{-2}$. Grain size analysis at this site (NR-6) determined that sediments primarily consist of unconsolidated silt and very fine sand. Observed current measurements have shown that velocities of $20 \mathrm{~cm} \mathrm{~s}^{-1}$ are common, which on a Hjulstrom diagram are sufficient to initiate transport of these sediment sizes. Accounting for the bulk density of the sediment removed indicates that the removal involved the top $2.2 \mathrm{~cm}$ of sediment. Utilizing meteorological data and in situ instrumentation (Hydrolab Minisonde with turbidity sensor and ADCP), increases in turbidity were recorded during periods of resuspension as measured by ${ }^{7} \mathrm{Be}$ and it was determined that these resuspension events occurred primarily during wind events $\geq 4 \mathrm{~m} \mathrm{~s}^{-1}$ (Giffin and Corbett, 2003). Peak events occurred mostly during the winter months as the result of northwesterly and northeasterly winds since these have the greatest fetch. Recent monitoring data suggest that an average of 55 resuspension events occur throughout the NRE on an annual basis (Dillard, 2008).

\section{Discussion}

\subsection{Water column nutrient dynamics}

The physical parameters DO, salinity, and temperature strongly influence biotic and water quality conditions in this estuarine system (Leuttich et al., 2000) and may be important in determining influences on bottom water nutrient concentration changes that result from resuspension events. Low DO conditions seem to correspond with contemporaneous increases of bottom water salinity and increased stratification in the upper estuary. Temperature changes, ranging from $9^{\circ} \mathrm{C}$ in the winter to $28^{\circ} \mathrm{C}$ in the summer, influenced seasonal changes in porewater nutrient distributions by increasing the available nutrient flux during the summer months. This is primarily due to increased microbial activity during the warmer conditions (Klump and Martens, 1981; Fisher et al., 1982; Hopkinson et al., 1999). Physical and chemical processes such as sediment resuspension, river discharge, and enhanced oxic conditions can influence nutrient concentrations in the water column, especially in the bottom water. Elevated $\mathrm{NH}_{4}^{+}$levels in the bottom water correlated with oxygen depletion (see Luettich et al., 2000). These elevated concentrations also corresponded with periods of sediment removal in the system. However, this is also a period of highest remineralization and diffusive flux.

Surface water showed elevated levels of $\mathrm{NO}_{3}^{-}$that could be the result of increased basin runoff since most of the $\mathrm{NO}_{3}^{-}$ input has been documented to occur during periods of high discharge (Christian et al., 1989; Boyer et al., 1994; Luettich et al., 2000). Similar results have been reported in other estuaries (Holmes et al., 2000). Additionally, increased nitrification during periods of sediment resuspension can contribute to these elevated $\mathrm{NO}_{3}^{-}$levels. Nitrate levels in the bottom water showed depletion during summer months, especially in the upper part of the estuary, due to a possible combination of benthic and plankton uptake (Christian et al., 
1991). Oxygen depletion, as indicated by the low DO concentrations in this area, could also account for this observation. The greater concentrations of $\mathrm{NH}_{4}^{+}$and $\mathrm{PO}_{4}^{3-}$ with depletion of $\mathrm{NO}_{3}^{-}$in the bottom waters could also partially be the result of heterotrophic consumption of organic matter sinking from surficial waters and denitrification (Cruzado et al., 2002). Nitrate concentrations typically constituted less than $20 \%$ of the total nitrogen budget available in the bottom waters during this study.

Several studies over the last two decades have sampled for these nutrients on a regular basis in the NRE (Christian et al., 1991; Luettich et al., 2000). In general, results showed $\mathrm{NO}_{3}^{-}$ranging from 20 to $350 \mu \mathrm{g} \mathrm{N}^{-1}$ in the latter half of the 1980's. Ammonium concentrations ranged from 10 to $73.4 \mu \mathrm{g} \mathrm{N} 1^{-1}$ and $\mathrm{PO}_{4}^{3-}$ from 9 to $147 \mu \mathrm{g} \mathrm{P} 1^{-1}$. In the 1990 's, $\mathrm{NO}_{3}^{-}$concentrations in surface water were typically $>600 \mu \mathrm{g} \mathrm{N}^{-1}$ in the upper estuary during the summer with occasional occurrences exceeding $1000 \mu \mathrm{g} \mathrm{N} 1^{-1}$. These larger excursions can usually be related to periods of increased river discharge. Ammonium was typically at levels between 50 and $150 \mu \mathrm{g} \mathrm{N}^{-1}$ with some concentrations exceeding $200 \mu \mathrm{g} \mathrm{N}^{-1}$ in the summer of 1996 , while $\mathrm{PO}_{4}^{3-}$ primarily was at 40 to $80 \mu \mathrm{g} \mathrm{P} 1^{-1}$ with some higher levels also during the summer months. Results from the mid-1990's indicated that total nitrogen and $\mathrm{PO}_{4}^{3-}$ median summer concentrations were $>100 \mu \mathrm{g} \mathrm{l}^{-1}$ (Luettich et al., 2000). A comparison of our results to these findings shows $\mathrm{NH}_{4}^{+}$and $\mathrm{PO}_{4}^{3-}$ at much higher levels, up to three times previous results, and lower $\mathrm{NO}_{3}^{-}$. However, several reasons for these variations are possible. Some of these studies primarily sampled from surface waters while our results also include bottom water sampling where sediment porewater fluxes of dissolved nutrients, especially $\mathrm{NH}_{4}^{+}$and $\mathrm{PO}_{4}^{3-}$, to overlying waters are less diluted. This could account for our higher concentrations of these constituents. The lower nitrate levels could possibly result from prolonged periods of decreased discharge during the year, $\mathrm{NO}_{3}^{-}$uptake, and/or the effect of ongoing nutrient management practices. However, when comparing total nitrogen $(\mathrm{TN})$ values across these studies there has been little change. Differences in $\mathrm{NO}_{3}^{-}$versus $\mathrm{NH}_{4}^{+}$between sampling events may just be a function of interannual variability due to differences in physical conditions such as DO availability and stratification. These nutrient concentrations are still at levels that can degrade water quality. Eutrophication can be sustained by nutrient recycling from sediments even after external nutrient reductions have occurred (Rizzo and Christian, 1996).

\subsection{Porewater gradients and flux}

Several mechanisms, such as temperature and/or salinity changes, bioirrigation, physical advective flushing (e.g. Huettel et al., 1998), and sediment resuspension, can alter porewater concentrations, and thus create non-steady state conditions. Porewater chemical reactions can be indicated by changes in the concentration gradient of a respective constituent. Near surface porewater nutrient profiles indicated an upward diffusion to the overlying water column. Strong temporal variation, as displayed during late summer, can indicate shifts in remineralization of organics and exchange of nutrients with the overlying water column (Hopkinson et al., 1999). Rapid shifts of this nature can cause important changes to equilibrium conditions. Due to the anaerobic nature of these sediments there are much greater $\mathrm{NH}_{4}^{+}$ concentrations than would be present under aerobic conditions. Therefore these changes to non-steady state could be significant.

Increased flux of nutrients from sediments can also occur through bioturbation (Tuominen et al., 1999), and during resuspension episodes,. However, no evidence of macrobenthic bioturbation was observed during this or previous studies (Matson et al., 1983; Cooper, 1998; Giffin and Corbett, 2003). Therefore, increased periods of flux are thought to be primarily the result of sediment remobilization. Generally, the occasional excursions of the diffusive porewater gradient conditions indicated bottom water uptake and corresponded to areas and timeframes of increased resuspension activity. The $\mathrm{NH}_{4}^{+}$and $\mathrm{PO}_{4}^{3-}$ profiles for NR-4 and NR- 6 during August, when the largest removal occurred, are indicative of this, as shown by their decreased gradients in the uppermost sediments (Figs. 5 and 6). Porewater $\mathrm{NH}_{4}^{+}$and $\mathrm{PO}_{4}^{3-}$ levels were also generally higher at all other times and locations of increased sediment removal (Figs. 5 and 6). Porewater $\mathrm{NO}_{3}^{-}$ increased an order of magnitude in August at all stations, indicating increased nitrification, but then declined back to low levels by fall. It should be noted that this occurred during a period when the lowest DO concentrations were observed. This increase in $\mathrm{NO}_{3}^{-}$was also coincident to the largest resuspension event, which could have increased vertical mixing (Kemp et al., 1990). Therefore, frequent sediment remobilization during this timeframe could have produced non-steady state conditions thereby enhancing nitrificationdenitrification in the surface sediments and bottom waters as is known to occur in other systems (Aller, 1998).

Many studies have shown a disagreement between measured and calculated flux using Fick's first law. In general, laboratory results have indicated lower calculated fluxes than in situ findings (Knox et al., 1993). While molecular diffusion flux calculations may be appropriate during quiescent periods, non-Fickian processes (e.g. advective transort via resuspension) could be considered more valid during times of greater mixing. During these more active sedimentary processes, gradient changes in the upper portions of the sediments indicate larger fluxes than can be justified using a diffusive approach. Advective flow is usually the result of a disturbance such as sediment resuspension, current/waveinduced porewater irrigation, bioturbation, or gas ebullition (Klump and Martens, 1981; Precht and Huettel, 2003) and is usually several orders of magnitude greater than diffusive 
Table 2. A comparison of the average diffusive and advective fluxes ( $\mathrm{mg} \mathrm{N}$ or $\mathrm{P} \mathrm{m}^{-2} \mathrm{~d}^{-1}$ ) from this and previous studies.

\begin{tabular}{llll}
\hline Study Reference & $\mathrm{PO}_{4}^{3-}$ flux & $\mathrm{NH}_{4}^{+}$flux & Method and Flow Assumption \\
\hline This study & 125 & 147 & Porewater gradient, advective \\
& 3 & 13 & Mean of porewater gradients, diffusion \\
Luettich et al, 2000 & - & 38 & Laboratory chamber, diffusion \\
Rizzo and Christian, 1996 & - & 34 & Unstirred cores, diffusion \\
Matson et al, 1983 & 8 & 25 & Porewater gradient, diffusion \\
Fisher et al, 1982 & - & 76 & In situ chamber, diffusion \\
\hline
\end{tabular}

flow. Therefore, a more realistic approach to determining actual fluxes of nutrients to the overlying water column during disturbance events would be the use of in situ concentration comparisons. By comparing nutrient inventories in bottom water and porewater before and after resuspension events and assuming little or no uptake, a determination of the effectiveness of advective release of nutrients can be made. $\mathrm{NRE}$ porewater $\mathrm{NH}_{4}^{+}$concentrations $\left(15.7 \mathrm{mg} \mathrm{N}^{-1}\right)$ were $\sim 40$ times that of the bottom water $\left(0.42 \mathrm{mg} \mathrm{N}^{-1}\right)$. Porewater $\mathrm{PO}_{4}^{3-}\left(13.1 \mathrm{mg} \mathrm{Pl}^{-1}\right)$ was 21 times bottom water $\mathrm{PO}_{4}^{3-}$ $\left(0.62 \mathrm{mg} \mathrm{Pl}^{-1}\right)$. This indicates the role that porewaters could play in supplying nutrients to the overlying water column, especially when sediments and porewaters are advected in removal episodes. It should be noted that resuspension is not the only process that could advect porewater nutrients into the overlying water column. As current velocities in bottom waters increase, small changes in topography may be sufficient to alter pressure gradients above the sediments and entrain and flush the porewaters. The ultimate result is the same, increased bottom water concentrations due to porewater advection, but the actual process varies. This type of physical advective flushing has been conducted in sandy sediments with ripples along the seabed (Huettel et al., 1998). Although the process cannot be ruled out in the NRE, sediments at sampling sites in this study consists almost entirely of muds ( $<63 \mathrm{um})$ with little macro-topography. As such, we compare the possible source of nutrients associated with observed resuspension events and acknowledge the potential for additional sources of porewater nutrients through other biological and physical processes. Seasonal comparisons have shown that the largest porewater and bottom water nutrient concentrations correspond to each other (August 2001) and are the same locations as the maximum removals through resuspension during this study. This illustrates the possible effectiveness of resuspension in releasing diagenetic endproducts from bottom sediments. This is also important because of the shift it will cause in increased denitrification and the eventual availability of nutrients for primary productivity.

For camparative purposes, an advective flux of nutrients can be estimated if a timeframe for a resuspension event is assumed. Using the porewater concentration for the uppermost sediments $(0-2 \mathrm{~cm}$; Figs. 5 and 6$)$ for the resuspen- sion event that occurred at NR-6 in August (2.2 cm removed; Giffin and Corbett, 2004) and assuming this removal event occured over approximately a $24 \mathrm{~h}$ timeframe, conservative $\mathrm{NH}_{4}^{+}$and $\mathrm{PO}_{4}^{3-}$ advective fluxes of $147 \mathrm{mg} \mathrm{N} \mathrm{m}^{-2} \mathrm{~d}^{-1}$ and $125 \mathrm{mg} \mathrm{P} \mathrm{m}^{-2} \mathrm{~d}^{-1}$, respectively, were estimated (note that a shorter period of time only increases the calculated porewater flux). Table 2 presents a comparison of the diffusive and advective flux calculations from this study to that found in several previous studies. $\mathrm{NH}_{4}^{+}$flux is typically 2 to 6 times greater using the advection approach than those with diffusion. Phosphate fluxes were determined to be 15 times greater than the benthic diffusive flux obtained in a prior study (Matson et al., 1983). It should be noted that $\mathrm{NH}_{4}^{+}$ diffusive flux during this study was at least half that determined in prior studies. This may be a result of averaging in fluxes from less dynamic periods of the study year. Calculations of flux at individual sites (Table 1) during the summer months and during periods of resuspension show values more representative of prior results.

\subsection{Management implications}

In 1998, North Carolina passed legislation calling for a 30\% reduction in $N$ loading to the NRE. However, this study has shown that total $N$ in the estuary remains at the same levels as were found prior to enactment of these nutrient reduction strategies. Several recent unpublished studies have indicated that riverine $N$ loading has decreased by at least $30 \%$ (Paerl, 2003). Meanwhile, non-point $N$ loading to the basin is rapidly increasing due to intensified animal production (Stow et al., 2001). The riverine loading decrease may be attributable to several natural factors outside of the effects of nutrient management legislation, including increased overland flow during 1999 (effects of Huricanes Dennis and Floyd) followed by several years of lower runoff and riverine discharge. Consequently, non-point nutrient loading to the river would also be diminished by this hydrological change.

The fact that total $N$ within the estuary remains the same during these low flow years combined with greater concentrations of $\mathrm{NH}_{4}^{+}$and $\mathrm{PO}_{4}^{3-}$ in bottom waters suggests the importance of accounting for internal loading sources such as groundwater infiltration and sediment disturbance. It has been estimated that the top $2 \mathrm{~cm}$ of sediments in the NRE 
contain 7800 tons of nitrogen (Luettich et al., 2000), while the water column has less than 800 tons (Christian et al., 1991). Furthermore, sediment storage and nutrient release is significant when typical riverine loading is compared to a resuspension event. Riverine $N$ loading to the estuary has been estimated to be about 13 tons daily (NCDENR 2001). A resuspension event of $\sim 2 \mathrm{~cm}$, assuming it occurs over only $25 \%$ of the estuary, can release as much as 17 tons of $N$. This is a conservative release based on calculations of an actual event in the lower estuary. The release would be higher if this event had occurred in the upper estuary where $N$ storage in the surficial sediments is greater or if it was to occur over a larger area. From an annual perspective, these resuspension events likely occur more than 50 times throughout the estuary (Dillard, 2008) and are caused by frequent wind events and the large fetch.

The greater concentration of $\mathrm{NH}_{4}^{+}$in bottom waters than shown in previous studies also indicates that denitrification may be decoupled from nitrification. It is generally thought that coupled nitrification-denitrification can remove $N$ from estuarine systems and may help to lessen the degree of eutrophication (Seitzinger, 1988). However, in some organic rich eutrophic estuaries, such as the Chesapeake, $\mathrm{NH}_{4}^{+}$is recycled directly back to the water column from the sediments without the occurrence of denitrification (Kemp et al., 1990). This increase in $\mathrm{NH}_{4}^{+}$recycling can be a consequence of greater mineralization of organic matter (Tuominen et al., 1999). It is also believed that anoxia in these estuaries may also reduce the effectiveness of denitrification (Nixon et al., 1996). The NRE portrays many of the same characteristics of Chesapeake Bay (i.e., organic-rich, eutrophic, episodes of anoxia), therefore similar changes in biogeochemical cycling of nitrogen could explain the lack of a decrease in total $\mathrm{N}$ within the estuary. Since internal loading can be as substantial as external riverine sources, these internal sources need to be considered in nutrient policy formulation.

\section{Summary}

Concentrations of porewater and bottom water nutrients increased to higher levels during resuspension events indicating increased denitrification and release of $\mathrm{NH}_{4}^{+}$and $\mathrm{PO}_{4}^{3-}$ to overlying waters. Bottom water conditions with elevated $\mathrm{NH}_{4}^{+}$and $\mathrm{PO}_{4}^{3-}$ indicate that nutrients stored in the sediments continue to play an important role in overall water quality in the estuary. Thus, evaluating the effect of advective flux from porewaters associated with resuspension events is important. The advective flux of $\mathrm{NH}_{4}^{+}$and $\mathrm{PO}_{4}^{3-}$ from porewaters were found to be at least 2 to 15 times those reported in previous studies of benthic diffusive flux. It should be noted that these results were obtained during a year of monitoring where there was only minor storm activity and low river discharge. The high concentrations of porewater nutrients and frequent resuspension events demonstrate the importance of an advective flux of nutrients in estuarine nutrient cycling.

Acknowledgements. Financial support for this study was provided to D. R. Corbett by NC Water Resources Research Institute under grant No. ECU-70187, NC Sea Grant under grant No. 1998-06170026 and East Carolina University under the Research/Creative Activity Grants program. Dan Giffin was an integral part of the field and laboratory efforts in this study. Stan Riggs provided invaluable information on the geological framework of the environment, leading toward the initiation of this study. I gratefully acknowledge Robert Reed of the Center for Applied Aquatic Ecology, North Carolina State University for providing meteorological and turbidity data from several locations on the NRE and Rick Luettich of the University of North Carolina for providing the use of a current meter. I would also like to thank Matt Allen, James Frank, Lorin Gaines, Kevin Miller, and Chris Foldesi for their help in sample collection and analysis.

Edited by: K. Küsel

\section{References}

Aller, R. C.: Mobile deltaic and continental shelf muds as suboxic, fluidized bed reactors, Mar. Chem., 61, 143-155, 1998.

American Public Health Association: Standard Methods for the Examination of Water and Wastewater, American Water Works Association, 1995.

Archie, G. E.: The electrical resistivity $\log$ as an aid in determining some reservoir characteristics, Trans. Am. Inst. Min. Metall., 146, 54-62, 1942.

Bengtsson, L., Hellstrom, T., and Rakoczi, L.: Redistribution of sediments in three Swedish lakes, Hydrobiolog., 192, 167-181, 1990.

Berner, R.: Early Diagenesis: A Theoretical Approach, Princeton University press, 241 pp., 1980.

Boyer, J. N., Stanley, D. W. Christian, R. R., and Rizzo, W. M.: Modulation of nitrogen loading impacts within an estuary, edited by: Lyke, W. L. and Hoban, T. J., in: Proceedings N.C. Amer. Water Resoures Assoc., Syposium on Coastal Water Resources. AWRA Technical Publ. Series TPS-88-1. AWRA, Bethesda, MD, 165-176, 1988.

Boyer, J. N., Stanley, D. W., and Christian, R. R.: Dynamics of $\mathrm{NH}_{4}^{+}$and $\mathrm{NO}_{3}^{-}$Uptake in the Water Column of the Neuse River Estuary, North Carolina, Estuaries, 17(2), 361-371, 1994.

Carper, G. L. and Bachman, R. W.: Wind resuspension of sediments in a Prairie Lake, Canad. Fish. Aq. Sci., 41, 1763-1767, 1984.

Christian, R. R., Rizzo, W. M., and Stanley, D. W.: Influence of nutrient loading on the Neuse River estuary, North Carolina, NOAA, National Underseas Research Program, Research Report, 89(2), 19-40, 1989.

Christian, R. R., Boyer, J. N., and Stanley, D. W.: Multi-year distribution patterns of nutrients within the Neuse River Estuary, North Carolina, Mar. Ecol. Prog. Ser., 71, 259-274, 1991.

Cooper, S. R.: The History of Water Quality in North Carolina Estuarine Waters as Documented in the Stratigraphic Record, Water Resources Research Institute, Raleigh, NC. Report No., 327, 1998. 
Corbett, D. R., Burnett, W. C., Cable, P. H., and Clark, S. B.: A multiple approach to the determination of radon fluxes from sediments, J. Radioanal. Nuc. Chem., 236, 247-252, 1998.

Cruzado, A., Velásquez, Z., del Carmen Pérez, M., Bahamón, N., Grimaldo, N. S., and Ridolfi, F.: Nutrient fluxes from the Ebro River and subsequent across-shelf dispersion, Cont. Shelf Res., 22, 349-360, 2002.

de Jonge, V. N. and van Beusekom, J. E. E.: Wind- and tide-induced resuspension of sediment and microphytobenthos from tidal flats in the Ems estuary, Limnol. Oceanog., 40, 766-778, 1995.

Dillard, S.: Resuspension events and seabed dynamics in the Neuse River Estuary, NC. MSc. Thesis, East Carolina University, p. 131, 2008.

Douglas, R. W. and Rippey, B.: The random redistribution of sediment by wind in a lake, Limnol. Oceanog., 45, 686-694, 2000.

Dugdale, R. C. and Goering, J. J.: Uptake of new and regenerated forms of nitrogen in primary productivity, Limnol. Oceanog., 12, 196-206, 1967.

Emmett, W., Leopold, L., Myrick, R.: Some characteristics of fluvial processes in rivers. In: International Symposium on River Sedimentation. Water Resources and Electric Power Press, Beijing, 1983.

Fanning, K. A., Carder, L. C., and Betzer, P. R.: Sediment resuspension by coastal waters: a potential mechanism for nutrient recycling on the ocean's margin, Deep-Sea Res. 29(8A), 953-965, 1982.

Fenchel, T.: What can ecologists learn from microbes: life beneath a square centimeter of sediment surface, Funct. Ecol., 6, 499507, 1992.

Fisher, T. R., Carlson, P. R., and Barber, R. T.: Sediment nutrient regeneration in three North Carolina Estuaries, Est. Coast. Shelf Sci. 14, 101-116, 1982.

Giese, G. L., Wilder, H. B., and Parker Jr., G. G.: Hydrology of major estuaries and sounds in North Carolina, U.S. Geological Survey Water Resources Investigation 79-46, Raleigh, NC. p. 175, 1979.

Giffin, D. A. and Corbett, D. R.: Evaluation of Sediment Dynamics in Coastal Systems Via Short-Lived Radioisotopes, J. Mar. Sys., 42, 83-96, 2003.

Haines, E. B.: Nitrogen content and acidity of rain on the Georgia coast, Water Res. Bull., 12, 1223-1231, 1976.

Hakanson, L. and Jansson, M.: Principles of lake sedimentology, Springer, 1983.

Hilton, J.: A conceptual framework for predicting the occurrence of sediment focusing and sediment redistribution in small lakes, Limnol. Oceanog., 30, 1131-1143, 1986.

Holmes, R. M., Peterson, B. J., Deegan, L. A., Hughes, J. E., and Fry, B.: Nitrogen Biochemistry in the Oligohaline Fone of a New England Estuary, Ecology, 81, 416-432, 2000.

Hopkinson, C. S., Giblin, A. E., Tucker, J., and Garritt, R. H.: Benthic Metabolism and Nutrient Cycling Along an Estuarine Salinity Gradient, Estuaries, 22, 863-881, 1999.

Huettel, M., Ziebis, W., Forster, S., and Luther III, G. W.. Advective transport affecting metal and nutrient distributions and interfacial fluxes in permeable sediments, Geochim. Cosmochim. Acta, 62, 613-631, 1998.

Kemp, W. M., Sampou, P., Caffrey, J., and Mayer, M.: Ammonium recycling versus denitrification in Chesapeake Bay sediments, Limnol. Oceanog., 35, 1545-1563, 1990.
Kirkham, D. and Powers, W. L.: Advanced Soil Physics, WileyInterscience, John Wiley and Sons Inc., New York, 1972.

Klump, J. and Martens, C. S.: Biogeochemical cycling in an organic rich coastal marine basin - II. Nutrient sediment-water exchange processes, Geochim. Cosmochim. Acta, 45, 101-121, 1981.

Knox, R. C., Sabatini, D. A., and Canter, L. W.: Subsurface Transport and Fate Processes, Lewis Publishers, Boca Raton, FL., 1993.

Kristensen, P., Sondergaard, M., and Jeppesen, E.: Resuspension in a shallow eutrophic lake, Hydrobiol. 228, 101-109, 1992.

Lam, D. C. and Jaquet, J.-L.: Computations of physical transport and regeneration of phosphorus in Lake Erie, fall 1970, J. Fish. Res. B. Can. 33, 550-563, 1976.

Luettich, R. A., Martens, C. S., McNinch, J. E., Pearl, H., Pinckney, J., Peterson, C. H., Wells, J. T. and Alperin, M. A.: Sedimentary Processes and Benthic-Pelagic Coupling, In: Neuse River Estuary MODeling and MONitoring Project, Water Resources Research Institute Report No. 325B, Raleigh, NC., 2000.

Luettich, R. A., Harleman, D. R. F., and Somlyody, L.: Dynamic behavior of suspended sediment concentrations in a shallow lake perturbed by episodic wind events, Limnol. Oceanog., 35, 10501067, 1990.

Matson, E. A., Brinson, M. M., Cahoon, D. D., and Davis, G. J.: Biogeochemistry of the Sediments of the Pamlico and Neuse River Estuaries, North Carolina. Water Resources Research Institute Report No. 191, Raleigh, NC., 1983.

Meade, R., Dunne, T., Richey, J., Santos, J., Santos, U., and Salati, E.: Storage and remobilization of suspended sediment in the lower Amazon River, Brazil, Science, 228, 488-490, 1985.

Meade, R., Yazyk, T., and Day, T.: Movement and storage of sediment in rivers of the United States and Canada, in: The Geology of North America, edited by: Woman H. Riggs, 1990.

Nichols, M. M.: Effects of fine sediment resuspension in estuaries, in Estuarine Cohesive Sediment Dynamics, edited by: Mehta, A. J., Springer-Verlag, 14, 1986.

Nixon, S. W.: Remineralization and nutrient cycling in the coastal marine ecosystem, in: Impact of Nutrient Enrichment in Estuaries, edited by: Neilson, B., Humana Press, 111-138, 1981.

Nixon, S. W., Ammerman, J. W., Atkinson, L. P., Berounsky, V. W., Billen, G., Boicourt, W. C., Boynton, W. R., Church, T. M., Ditoro, D. M., Elmgren, R., Garber, J. H., Giblin, A. E., Jahnke, R. A., Owens, N. J. P., Pilson, M. E. Q., and Seitzinger, S. P.: The fate of nitrogen and phosphorus at the land-sea margin of the North Atlantic Ocean, Biogeochem., 35, 141-180, 1996.

Paerl, H. W., Dennis, R. L., and Whitall, D. R:. Atmospheric Deposition of Nitrogen: Implications for Nutrient Over-enrichment of Coastal Waters, Estuaries, 25, 677-693, 2002.

Pilkey, O. H., Neal, W. J., Riggs, S. R., Webb, C. A., Bush, D. M., Pilkey, D. F., Bullock, J., and Cowan, B. A.: The North Carolina Shore and its Barrier Island, Duke University Press, Durham, 1998.

Pipkin, B.: Geology and the Environment, West Publishing Co., Minneapolis, MN., 1994.

Postma, H.: Sediment transport and sedimentation in the estuarine environment, edited by: Lauff, G. H., in: Estuaries, Publication No. 83, AAAS, Washington, D.C., 158-179, 1967.

Precht, E. and Huettel, M.: Advective pore-water exchange driven by surface gravity waves and its ecological implications, 48, 1674-1684, 2003. 
Riggs, S. R., Bray, J. T., Powers, E. R., Hamilton, J. C., Ames, D. V., Owens, K. L., Yeates, D. D., Lucas, S. L., Watson, J. R., and Williamson, H. M.: Heavy metals in organic-rich muds of the Neuse River estuarine system, Albemarle-Pamlico Estuarine Study, Report No. 90-07, 1991.

Riggs, S. R.: Sediment Evolution and Habitat Function of OrganicRich Muds Within the Albemarle Estuarine System, North Carolina. Estuaries, 19, 169-185, 1996.

Rizzo, W. M.: Sediment-water phosphate exchange in the Neuse River, North Carolina, North Carolina Water Resources Research Institute Report No. 275, p. 64, 1993.

Rizzo, W. M. and Christian, R. B.: Significance of Subtidal Sediments to Heterotrophically-Mediated Oxygen and Nutrient Dynamics in a Temperate Estuary, Estuaries, 19, 475-487, 1996.

Seitzinger, S. P.: Denitrification in freshwater and coastal marine ecosystems: Ecological and Geochemical significance, Limnology and Oceanography, 33, 702-724, 1988.

Solorzano, L.: Determination of ammonia in natural waters by the phenol-hypochlorite method, Limonl. Oceanog., 14, 799-801, 1998.

Sondergaard, M., Kristensen, P., and Jeppesen, E.: Phosphorus release from resuspended sediment in the shallow and windexposed Lake Arreso, Denmark, Hydrobiolog., 228, 91-99, 1992.

Spruill, T. B., Harned, D. A., Ruhl, P. A., Eimers, J. L., Galeone, D. R. McMahon, G., Smith, K. E., and Woodside, M. D.: Water quality in the Albemarle-Pamlico Drainage Basin, North Carolina and Virginia, 1992-95. Circ. 1157, United States Geol. Survey, Reston, VA., 1998.

Stanley, D. W. and Hobbie, J. E.: Nitrogen cycling in a North Carolina coastal river, Limnol. Oceanog., 26, 30-42, 1981.

Stow, C. A., Borsuk, M. E., and Stanley, D. W.: Long-term Changes in Watershed Nutrient Inputs and Riverine Exports in the Neuse River, North Carolina, Water Res., 35(6), 1489-1499, 2001.
Tenore, K. R.: Macrobenthos of the Pamlico River Estuary, North Carolina, Ecolog. Monog., 42(1), 51-69, 1972.

Tuominen, L., Mäkela, K., Lehtonen, K. K., Haahti, H., Hietanen, S., and Kuparinen, J.: Nutrient Fluxes, Porewater Profiles and Denitrification in Sediment Influenced by Algal Sedimentation and Bioturbation by Monoporeia affinis. Est. Coast. Shelf Sci., 49, 83-97, 1999.

US Environmental Protection Agency: Methods for Chemical Analysis of Water and Wastewater, Environmental Monitoring and Support Laboratory, Cincinnati, OH., 1997.

US Environmental Protection Agency: Methods for the Determination of Chemicals in Marine and Estuarine Environmental Matrices, National Exposure Research Laboratory, Cincinnati, $\mathrm{OH}$., 1997.

Webster, I. T., Norquay, S. J. Ross, F. C., and Wooding, R. A.: Solute Exchange by Convection Within Estuarine Sediments, Est. Coast. Shelf Sci., 42, 171-183, 1996.

Wells, J. T. and Kim, S. Y.: Sedimentation in the AlbemarlePamlico Lagoonal System: Synthesis and Hypotheses, Mar. Geol., 88, 263-284, 1989.

Weyhenmeyer, G. A., Hakanson, L., and Meili, M.: A validated model for daily variations in the flux, origin, and distribution of settling particles within lakes, Limnol. Oceanog. 42, 1517-1529, 1997.

Windom, H. L., Dunstan, W. M., and Gardner, W. S.: River input of inorganic phosphorus and nitrogen to the southeastern salt marsh estuarine environment, Recent Adv. in Est. Res., 1, 309313, 1975.

Woods, W. J.: Current study in the Neuse River and estuary of North Carolina, North Carolina Water Resources Research Institute Report No. UNC-WRRI-69-13, 1969. 